BMC

Evolutionary Biology

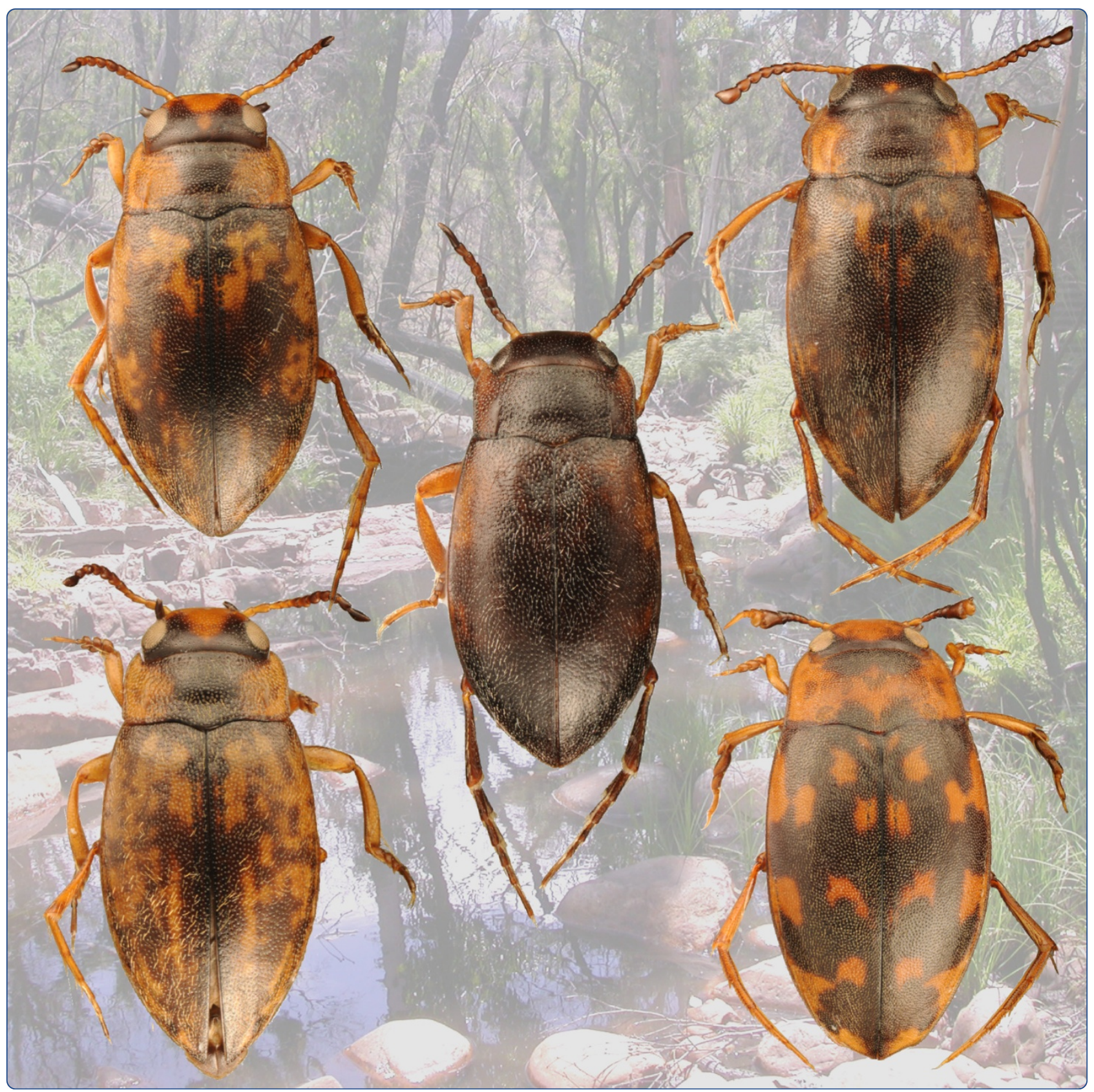

\title{
Pleistocene climate change promoted rapid diversification of aquatic invertebrates in Southeast Australia
}

Hawlitschek et al. 


\title{
Pleistocene climate change promoted rapid diversification of aquatic invertebrates in Southeast Australia
}

Oliver Hawlitschek ${ }^{*}$, Lars Hendrich', Marianne Espeland ${ }^{2}$, Emmanuel FA Toussaint ${ }^{1}$, Martin J Genner ${ }^{3}$ and Michael Balke $e^{1,4}$

\begin{abstract}
Background: The Pleistocene Ice Ages were the most recent geohistorical event of major global impact, but their consequences for most parts of the Southern hemisphere remain poorly known. We investigate a radiation of ten species of Sternopriscus, the most species-rich genus of epigean Australian diving beetles. These species are distinct based on genital morphology but cannot be distinguished readily by mtDNA and nDNA because of genotype sharing caused by incomplete lineage sorting. Their genetic similarity suggests a Pleistocene origin.

Results: We use a dataset of 3858 bp of mitochondrial and nuclear DNA to reconstruct a phylogeny of Sternopriscus using gene and species trees. Diversification analyses support the finding of a recent rapid speciation event with estimated speciation rates of up to 2.40 species per MY, which is considerably higher than the proposed average rate of 0.16 species per MY for insects. Additionally, we use ecological niche modeling and analyze data on habitat preferences to test for niche divergence between species of the recent Sternopriscus radiation. These analyses show that the species can be characterized by a set of ecological variables referring to habitat, climate and altitude.

Conclusions: Our results suggest that the repeated isolation of populations in glacial refugia might have led to divergent ecological adaptations and the fixation of morphological traits supporting reproductive isolation and therefore may have promoted speciation. The recent Sternopriscus radiation fulfills many characteristics of a species flock and would be the first described example of an aquatic insect species flock. We argue that the species of this group may represent a stage in speciation past the species flock condition because of their mostly broad and often non-overlapping ranges and preferences for different habitat types.
\end{abstract}

\section{Background}

Global biodiversity is shaped by the processes of speciation and extinction, whose rates vary depending on region, environment, taxonomic group and geohistorical events [1-3]. Evidence for shifts in the rates of speciation and extinction have been inferred from the fossil record since early paleontology [4], and advances in molecular biology have greatly improved our capabilities to study these processes particularly for taxa with sparse or inconsistent fossil evidence $[5,6]$.

\footnotetext{
* Correspondence: oliver.hawlitschek@gmx.de

'Zoologische Staatssammlung, Münchhausenstr. 21, Munich 81247, Germany Full list of author information is available at the end of the article
}

The most recent geohistorical event of major global impact on biodiversity was the Pleistocene glaciations, or Ice Ages, which represent the largest expansion of cold climates since the Permian period 250 million years (MY) earlier. Until 10,000 years ago, temperatures repeatedly oscillated between warm and cold phases. The effects on the environment varied depending on geographical region, but were always accompanied by major biotic shifts. Boreal regions, particularly in the Northern hemisphere, were mostly glaciated and drove species into refugia [7]. In the tropics and subtropics, where glaciations were mostly restricted to high altitudes, a similar effect was attributed to the aridification of formerly humid forest habitats [8]. It has been a matter of discussion whether these cycles of environmental change

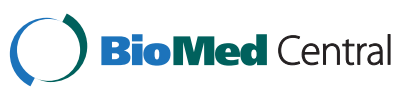


promoted speciation [9] or whether species responded solely by shifting their ranges toward ecologically suitable areas [10]. In Australia, glaciations occurred only at its highest elevations, but biota faced an ongoing process of aridification that was initiated in the Miocene $c .15$ million years ago (MYA) when Australia drifted northward [11]. During the Ice Ages, the relatively rapid shifts between warm and wet versus cold and dry conditions had severe consequences particularly for the fauna $[12,13]$. Aquatic environments were strongly affected by oscillations between arid and humid conditions [14].

The genesis of the Australian arid zone promoted radiations in various organism groups, e.g., hypogean faunas in the ground waters underneath the spreading deserts, which most likely began with the onset of the aridification c. 15 MYA [14]. However, many rapid radiations of insects dating back only $2 \mathrm{MY}$ or less have been described from all around the world. Coyne \& Orr [15] proposed an average speciation rate of 0.16 species per MY, which is exceeded by an order of magnitude by the fastest known radiation [16-18]. Phylogenies of such young radiations based on mitochondrial gene trees are often poorly resolved, and species may appear para- or polyphyletic because of shared alleles with other species, which may be the result of incomplete lineage sorting or hybridization [19]. Species trees may cope with these problems: in a method based on a coalescent model and Bayesian inference, all gene trees are co-estimated and embedded in a single species tree whose tips represent species and not single samples [20,21].

Aside from morphological and molecular characters, ecological factors can be useful to distinguish and even delimit species. Many studies have shown that a variety of climate factors often have a profound effect on the distributions of species, and these factors can be combined to project potential distributions of species in an Ecological Niche Modeling (ENM) approach [22,23]. The predictive powers of this method have been demonstrated [24], and it has been successfully applied in species delimitations [22,25]. Naturally, the distinction of species based on differences in their responses to ecological factors is sensible only if there are actual response differences. Evidence of niche conservatism in closely related species, promoting allopatric speciation, is abundant [26]. However, in many examples of rapid radiations in limited geographic areas niche divergence appears to be the more common condition, and closely related species show different responses to ecological factors [2004, 27].

The focus of our study is on the genus Sternopriscus (Coleoptera: Dytiscidae: Hydroporini), which is the most species-rich epigean genus of Australian diving beetles and contains 28 species [27,28]. Sternopriscus species inhabit a wide variety of lentic and lotic habitats from sea level to high altitudes. 18 species are found in southeastern Australia, of which four species are endemic to Tasmania. The corresponding freshwater ecoregions according to Abell et al. [29] are Eastern Coastal Australia, Bass Strait Drainages, Southern Tasmania, and small parts of the Murray-Darling region. Unlike many other aquatic invertebrates, such as crustaceans and gastropods, most species of epigean aquatic beetles use flight to colonize new habitats. Therefore, the presence of suitable habitats most likely has a higher impact on aquatic beetle distribution than the drainage systems defining the biogeographic regions of Abell et al. [29]. Nevertheless, only 2 of these 18 species have a wider distribution over mainland Australia (S. multimaculatus and S. clavatus). 6 species, including some taxonomically and geographically isolated species, are endemic to peaty habitats in the southwest, in an area with cold and humid climate during winter, and 5 species are distributed over the tropical north, including one endemic species in the deep gorges of the Pilbara. None, or only one, species is shared by 2 or more of these areas of endemism. This distribution reflects the restriction of all but the widespread pioneer species S. multimaculatus to the more humid coastal areas of Australia. The high level of endemism in the southeast and southwest suggests that the arid barrier between these two regions is long-standing. Another strong pattern is the virtual absence of $S$. tarsalis group members from the north and southwest regions of the continent, whereas members of the S. hansardii group, with highly modified male antennae and median lobes, are more widespread $[27,28]$.

Based on male morphological characters, the genus has been divided into 3 groups: the $S$. hansardii group (11 species), the $S$. tarsalis group (13 species), and 4 'phylogenetically isolated' species. The species in the $S$. tarsalis group have been assigned to 3 species complexes: the $S$. tarsalis complex (2 species), the $S$. meadfootii complex (5), and the S. tasmanicus complex (3). 3 species have not been assigned to any complex. The 10 species belonging to the S. tarsalis, S. meadfootii and $S$. tasmanicus complexes in the $S$. tarsalis group are genetically similar and centered in mesic southeastern Australia. Below, we refer to this group of species as the S. tarsalis radiation (STR). The STR is supposedly the result of recent diversification; some of these morphologically well-defined species occur in sympatry, and some in syntopy $[27,28,30]$. Previous genetic studies [30] suggest that species belonging to the STR are not easily delimited using mtDNA and nDNA.

In this study, we attempt to test the following hypotheses: (1) the delimitation of species in the STR, based on morphological characters, can be supported by genetic or ecological data; (2) the STR species originated in a rapid and recent diversification event, most likely in the 
Pleistocene; and (3) the radiation of the STR was promoted by the Pleistocene climate oscillations. We use a molecular phylogeny with gene and species trees and diversification rate analyses to investigate how environmental change has affected speciation and extinction rates in the genus Sternopriscus. We then discuss which factors might have promoted lineage diversification in the STR and whether the molecular similarities are caused by hybridization or incomplete lineage sorting. Aside from the results of our molecular phylogeny, we use phylogeographic network analyses and ENM paired with empirical ecological data in an attempt to reveal how this diversification was promoted.

\section{Methods}

\section{Sampling and laboratory procedures}

Specimens were collected by sweeping aquatic dip nets and metal kitchen strainers in shallow water or operating black-light traps [27] and preserved in 96\% ethanol. DNA was extracted non-destructively using Qiagen blood and tissue kits (Qiagen, Hilden). Primers are listed in Additional file 1: Table S1. New sequences were submitted to GenBank under accession numbers [EMBL: HE818935] to [EMBL:HE819178]; cox1 data are [EMBL: FR732513] to [EMBL:FR733591]. The individual beetles from which we extracted and sequenced DNA each bear a green cardboard label that indicates our DNA extraction number (e.g., "DNA 1780 M. Balke"). This number links the DNA sample, the dry mounted voucher specimen and the GenBank entries.

\section{Phylogenetic analyses}

The aligned 3858 bp dataset contains three mitochondrial (16 S rRNA, cytochrome oxidase b $(c o b)$, and cytochrome $c$ oxidase subunit I (cox1)) and four nuclear gene fragments (18 S rRNA, arginine kinase (ARK), histone 3 (h3), and histone 4 (h4)) for 54 specimens of 25 Sternopriscus species and 2 Hydroporini outgroups, Barretthydrus stepheni and Carabhydrus niger. Among the known species of Sternopriscus, only S. mouchampsi and S. pilbaraensis were not available for sequencing. S. emmae was excluded from the phylogenetic analyses because we only had DNA from museum specimens and only obtained a short cox1 sequence. DNA alignment was performed in MUSCLE 3.7 [31]. We then used jModelTest 0.1.1 [32] to identify appropriate substitution models for each gene separately, assessing $\operatorname{lnL}$, AIC and BIC results and giving preference to BIC. To evaluate different partition schemes, we performed a Bayes factor test with MrBayes 3.1 [33] and Tracer v1.5 [34]. The eleven schemes tested were mitochondrial versus nuclear, protein-coding versus ribosomal, and according to codon positions $(1+2$ versus 3 or one partition for each codon position). We used raxmlGUI 0.93 [35] for maximum likelihood analyses with 1000 fast bootstrap repeats. MrBayes 3.1 [33] was used for Bayesian analyses, with two runs and four chains with 30,000,000 generations (samplefreq $=1,000$ and 25\% burnin). Runs were checked for convergence and normal distribution in Tracer v1.5 [34]. We then used parsimony analysis to infer phylogenetic relations as implemented in the program TNT v1.1, which we also used to run 500 jackknife replications (removal 36\%) to assess node stability [36] (hit the best tree 5 times, keep 10,000 trees in memory). Finally, we used coalescent-based species tree inference models in *BEAST v1.6.1 [21] for comparison with the results of the phylogenetic gene tree. "BEAST requires a-priori designation of species, which we performed based on morphological data $[27,28]$. We conducted two runs over 100,000,000 generations (sample freq $=1,000$ and $20 \%$ burnin) and checked for convergence and normal distribution in Tracer v1.5 [34]. Additionally, as proposed in Pepper et al. [13], we repeated this analysis using simpler substitution models $(\mathrm{HKY}+\mathrm{G})$. All analyses in MUSCLE and MrBayes were run on the CIPRES Portal 2.2 [37]. Pairwise distances were calculated in MEGA 5.0 [38].

\section{Lineage diversification and radiation}

Analyses were conducted in $\mathrm{R}$ with the packages APE [39] and Laser [40]. Based on the phylogenetic tree created in MrBayes, we used the 'chronopl' function of APE to create an ultrametric tree in $\mathrm{R}$ and cropped all representatives but one of each species. We then constructed Lineage-Through-Time (LTT) plots [41] and calculated $\gamma$-statistics [42]. Because new species continue to be discovered in Australia and incomplete taxon sampling might influence $\gamma$-statistics, we conducted a Monte Carlo constant rates (mccr) test with 10,000 replicates, assuming $10 \%$ missing species. We then tested the fit of two rate-constant [41] and four rate-variable diversification models [43] to our dataset. Finally, we calculated $p$-values by simulating 10,000 trees with original numbers of present and missing species for a pure-birth scenario and for various birth-death rates $(b=0.5$ and $\mathrm{d}=0.0,0.25,0.5,0.75$ and 0.9$)$. To be able to understand the effect of the near-tip radiation in the STR, we also tested $\gamma$ for a tree in which this group was treated as a single taxon.

Because of a lack of reliable calibration points, we cannot rely on molecular clock analyses to estimate node ages in the Sternopriscus phylogeny. However, we attempt to approximate the age of the rapid radiation in the STR using the standard mutation rates of the cox 1 gene $[44,45]$. We apply the equation presented in Mendelson \& Shaw [16] to estimate the relative speed of this radiation for comparison with other known rapid radiations in insects. For young and monophyletic radiations, 
such as the STR, the equation is $\hat{r}=\ln N / t$, where $\hat{r}$ is the rate of diversification, $\mathrm{N}$ is the number of extant species, and $t$ is the divergence time.

\section{Phylogeographic structure analysis}

We assembled a matrix of 710 bp of only cox 1 for 79 specimens of STR species to investigate the phylogeographic structure of this group. Additional sequences were obtained from Hendrich et al. [30]. The standard population genetic statistics Fu's Fs [46] and Tajima's D [47] were calculated, and mismatch distribution analyses to untangle demographic histories were performed using DnaSP 5.10 [48]. The multiple sequences were collapsed in haplotypes also using DnaSP 5.10. A minimumspanning network was then inferred in Arlequin 3.5.1.3 [49] and used to create a minimum-spanning tree (MST) using Hapstar 0.5 [50]. The scalable vector graphics editor Inkscape 0.48 was further used to map geographic and taxonomic information on the MST.

\section{Distinguishing incomplete lineage sorting from hybridization}

We used an approach developed by Joly et al. [51], and employed in Joyce et al. [52] and Genner \& Turner [53] to test whether the haplotype sharing between STR species was mainly the result of incomplete lineage sorting or influenced by hybridization. In this approach, mtDNA evolution is simulated using a species tree topology that assumes hybridization is absent. If low genetic distances between species pairs are due to incomplete lineage sorting, these similarly low genetic distances should be observed in the simulations. If low genetic distances between species pairs are due to hybridization, then significantly lower genetic distances should be present than observed in the simulations. First, we ran another "BEAST [21] analysis of a subset of the entire multilocus dataset containing only the STR species, using the HKY + G model for 11,000,000 generations (samplefreq $=1,000$ and $10 \%$ burnin). Second, we used MrModeltest [54] to estimate the parameters of the substitution model for the cox1 dataset from Hendrich et al. [30], which was previously used in the phylogeographic structure analysis. Third, we conducted a run of the JML software [55] using the same cox1 dataset, the locus rate of cox 1 as yielded by "BEAST, a heredity scalar of 0.5 , and the parameters yielded by MrModeltest.

\section{Ecological niche modeling and analyses}

In an attempt to detect possible divergence in response to climatic variables in their ranges, we created ecological niche models (ENMs) for the species of the STR. We excluded $S$. montanus and $S$. williamsi from the ENM analyses because of an insufficient number of localities. Our models were based on a total of 215 distribution points $[27,28]$ (Additional file 2: Table S2) and unpublished data by L. Hendrich. With the exception of three records of S. wehnckei, all STR species occur in broad sympatry in southeastern Australia including Tasmania.

We preliminarily selected climate variables according to ecological requirements considered critical for the species. Bioclimatic variables [56] represent either annual means or maxima and minima in temperature and precipitation, or variables correlating temperature and precipitation, e.g., "mean temperature of wettest quarter" (BIO8). Such variables are useful for representing the seasonality of habitats [25]. After the preliminary selection, we used the ENMtools software [57] to calculate correlations between the selected climate layers in the area of interest. In our final selection, we removed layers until no two layers had correlation coefficients $\left(\mathrm{r}^{2}\right)$ higher than 0.75. ENMs for each species were created in Maxent 3.3.2 [58] (our procedure: Hawlitschek et al. [25]). Suitable background areas that were reachable by the species were defined by drawing minimum convex polygons around the species records, as suggested by Phillips et al. [59]. We conducted runs with 25\% test percentage, 100 bootstrap repeats, jackknifing to measure variable importance and logistic output format. Model validation was performed by calculating the area under the curve (AUC) [60]. To compare ENMs of different Sternopriscus species, we measured niche overlap [57] in ENMtools. We also used ENMtools' niche identity test [61] with 500 repeats because the niche overlap values alone do not allow any statements whether the ENMs generated for the two species are identical or exhibit statistically significant differences. In each repeat of this test, pairwise comparisons of species distributions are conducted and their localities pooled, their identities are then randomized and two new random samples are extracted to generate a set of pseudoreplicates. The results are compared with the true calculated niche overlap (see above). The lower the true niche overlap is in comparison to the scores created by the pseudoreplicates of the pooled samples, the more significant the niche difference between the two compared species. Finally, we classified species by altitudinal and habitat preference and compared all data.

\section{Results}

\section{Molecular phylogenetics}

Bayes factor analyses favored separate partitioning of genes and codon positions (17 partitions in total). This was the most complex partition strategy tested. Substitution models applied were according to jModeltest: the GTR + I + G model (16 S rRNA, mitochondrial non-protein-coding), the GTR + G model (cox1, cob, mitochrondrial protein-coding), the HKY $+\mathrm{I}+\mathrm{G}$ 
model (18 S rRNA, nuclear non-protein-coding), and the HKY + G model (ARK, h3, h4, nuclear proteincoding). Bayesian, maximum likelihood, and maximum parsimony analyses revealed compatible topologies (Figure 1) that were largely congruent with the previously recognized classifications based on morphology. Here, we assign the four species previously supposed to be 'phylogenetically isolated' to either the $S$. tarsalis ( $S$. browni and S. wattsi), or the S. hansardii (S. eikei and $S$. marginatus) group. Within the $S$. tarsalis group, all S. tarsalis complex species form a strongly supported clade (Figure 1).

The "BEAST species tree is largely congruent to the gene trees. The main difference is that in the gene trees,

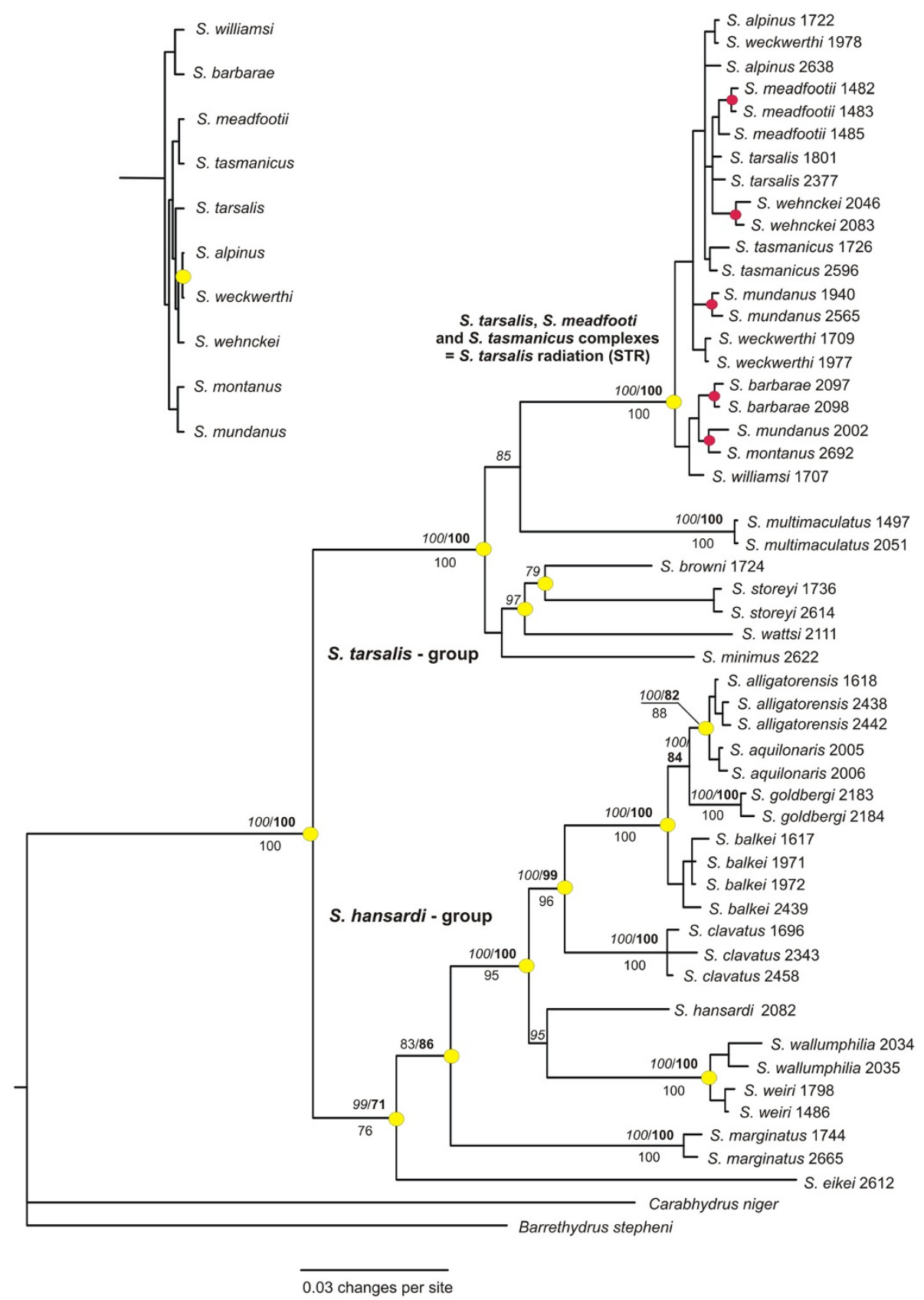

Figure 1 Phylogram of the genus Sternopriscus. The phylogram is based on a MrBayes tree with 7 gene loci and 3858 characters. Branch values are: MrBayes posterior probability (italic/above branch), RAxML bootstrap (bold/above branch), and TNT jackknife (below branch). Yellow circles mark nodes with *BEAST species tree posterior probabilities of 75 or more. Red circles mark nodes within the S. tarsalis radiation with PP, bootstrap and jackknife values of 75 or more (values not shown for layout reasons). Each tip represents one specimen. Specimen collection numbers are given after the species names. Upper left: *BEAST species tree fragment showing the $S$. tarsalis radiation specimens. 
S. multimaculatus is the sister taxon to the STR, whereas in the "BEAST tree $S$. minimus is the sister taxon to the STR and S. multimaculatus is the sister taxon to all other members of the $S$. tarsalis group. Almost all species tree nodes within the STR are poorly supported. Notably, the analysis of the *BEAST run log file showed near-critically low posterior and prior effective sample sizes $(<120)$. This problem could neither be solved by repeating runs with higher sample frequencies nor with the application of simpler substitution models, as proposed in Pepper et al. [13], and indicates that the species tree results must be treated with caution.

The largest calculated cox $1 p$-distance between species in the STR was only $3.4 \%$ (S. tarsalis/S. barbarae), but interspecific distances may be as low as $0.3 \%$ (e.g., between $S$. alpinus, S. mundanus and $S$. weckwerthi, all belonging to different $S$. tarsalis complexes) or $0.2 \%$ (S. alpinus/S. wehnckei). Thus, no genetic distinction between the three complexes was possible because specimens often cluster with those belonging to other morphologically well-characterized species. This problem could not be solved by inspecting trees based on single or combined nuclear loci; the species S. mundanus and $S$. weckwerthi were polyphyletic in single-gene trees of cob, cox 1, and ARK. The STR species shared identical haplotypes in all other nuclear genes studied.

\section{Diversification analyses}

Figure 2 shows the LTT plot for Sternopriscus. APE yielded a positive $\gamma$ value of $3.22\left(\mathrm{p}=0.0013^{*}\right)$. According to the mccr test, the critical value is $1.73\left(\mathrm{p}=0.9^{*} 10 \mathrm{E}-3^{* *}\right)$ and is

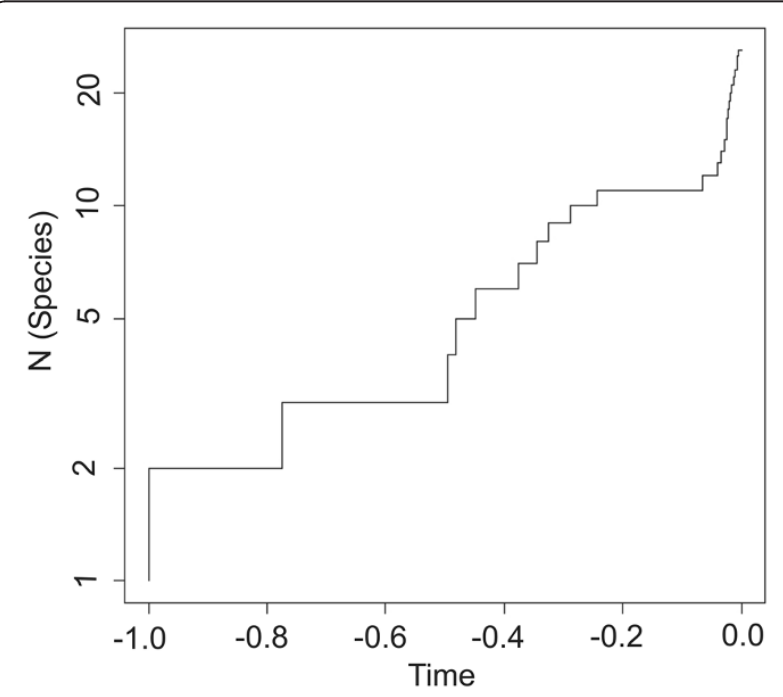

Figure 2 Lineage-through-time (LTT) plot for the genus Sternopriscus. Relative time $(-1.0$ is the time of the initial lineage split within the genus, 0.0 is the present) is given on the $x$-axis, number of species is given logarithmically on the $y$-axis. therefore met by the true value of $\gamma$. The test in Laser yielded a Yule-2-rate model as significantly better than the next best model, which was a constant rate birth-death model. The level of significance was highest $\left(\mathrm{p}=0.0073^{*}\right)$ for equal rates of $\mathrm{b}$ (birth) and $\mathrm{d}$ (death) (both 0.5), but all tested combinations of $\mathrm{b}$ and $\mathrm{d}$ yielded significant test results. In the test run in which the $S$. tarsalis-group was treated as a single clade, $\gamma$ was negative but not significant at a value of $-0.01(p=0.4956)$. This means that for this dataset the null hypothesis that the diversification rates have not decreased over time cannot be rejected.

The STR appears to have a thorough effect on the diversification analysis of the genus Sternopriscus. A high positive $\gamma$ represents a rather unusual condition [6]. While many phylogenies are characterized by a decreasing rate of diversification (logistic growth or impact of extinctions [62]), a $\gamma=3.22$ suggests a diversification rate that is highly increasing over time. This pattern is hard to explain in general. In the case of Sternopriscus, it appears appropriate to attribute this pattern to the recent speciation burst of the STR, which comprises 10 of 28 known species. This view is also supported by the test results that indicate a Yule-2-rate model as the most adequate, which fits to a sudden shift in diversification rates.

Papdopoulou et al. [44] suggested using substitution rates of $3.54 \% \operatorname{cox} 1$ divergence per MY which suggest an origin of the STR c. 0.96 MYA, and interspecific distances indicate divergence times as recent as 60,000 to 80,000 years ago. The slower substitution rate (2.3\%) suggested by Brower [45] yields an approximate origin of the STR around 1.48 MYA and interspecific divergence times of 87,000 to 130,000 years ago (but see Papadopoulou et al. [44] for a discussion of these estimates). The equation by Mendelson \& Shaw [16] was used to estimate speciation rates in the STR. Applying the proposed rate of Papdopoulou et al. [44], we estimate a speciation rate in the STR of 2.40 species per MY. Applying the proposed rate of Brower [45], we estimate a speciation rate in the STR of of 1.56 species per MY.

\section{Phylogeographic structure}

The matrix of $79 \operatorname{cox} 1$ sequences contained 69 polymorphic sites with a nucleotide diversity of $\pi=0.0121$ and a haplotype diversity of $\mathrm{H}=0.9815$. We identified 61 distinct and mostly unique haplotypes within the STR with only 8 haplotypes comprising more than one sequence. Neither geographic nor taxonomic (Figure 3) mapping on the star-like MST yielded a comprehensive pattern. More precisely, no geographic structuring could be noticed based on the zoning of Australia, and the haplotypes of individuals of identical species were not systematically gathered in groups. Interestingly, the MST 


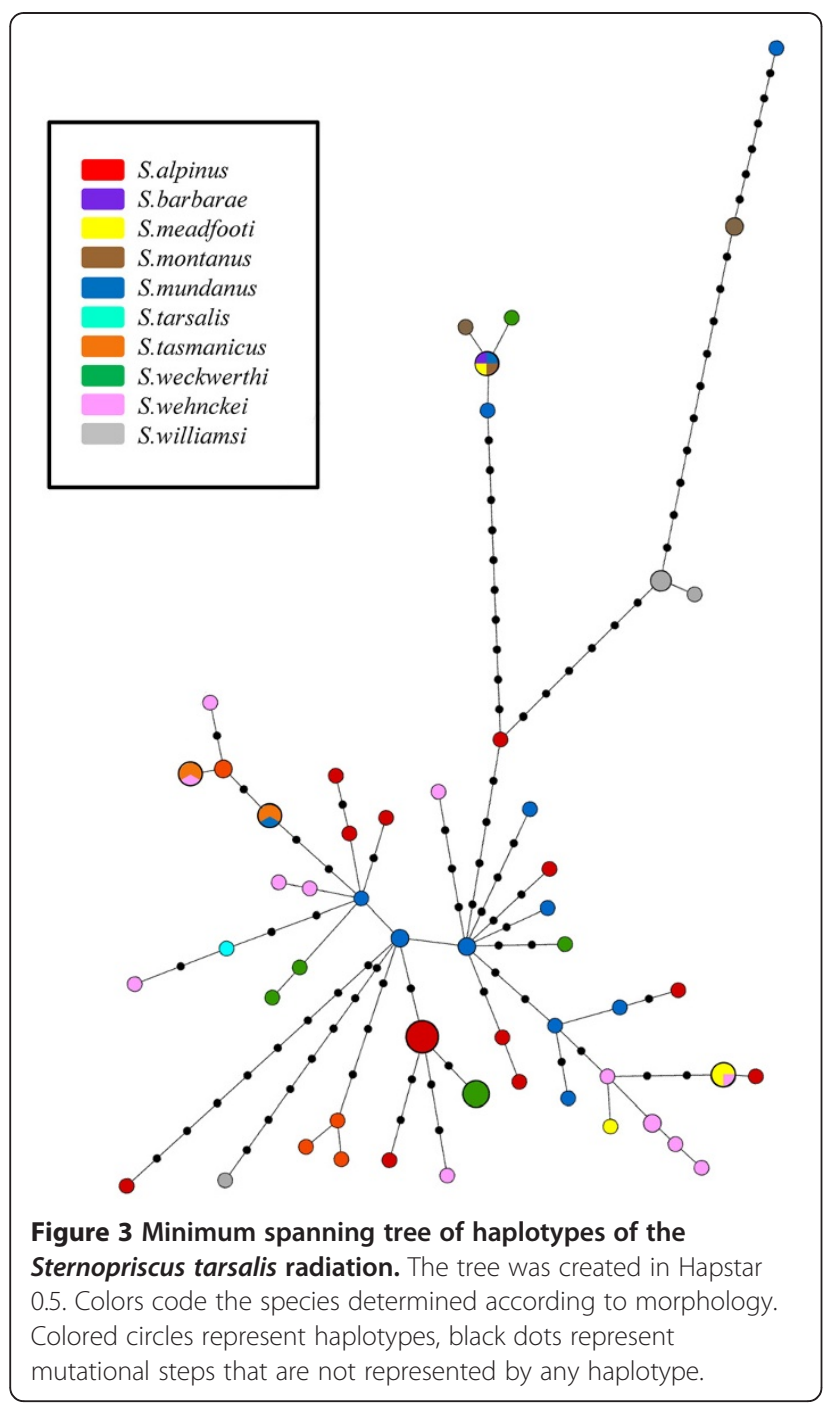

appears to be composed of two central haplotypes of South Australian and Victorian S. mundanus from which the rest of the sequences appears to have derived. In addition, even if there is a lack of geographical or taxonomic structuration, one might notice that several haplotypes representing different species are separated from the central network by a deep break of multiple mutation steps. While Tajima's D value does not significantly support a scenario of demographic expansion $(\mathrm{D}=-1.27773$, $\mathrm{p}$-value $=0.06)$, Fu's Fs significantly support such a demographic history $(\mathrm{Fs}=-35.731$, p-value $=0.01)$ (see Tajima [47] and Fu [46] regarding the interpretation of Tajima's and Fu's statistics). However, the mismatch distribution analyses yield a multimodal distribution of the pairwise genetic distances, which favors a scenario of demographic equilibrium for the STR even if unimodal distributions are recovered only for recent and fast expansions [63].

\section{Incomplete lineage sorting vs. hybridization}

"BEAST yielded a high relative locus rate of 2.332 for cox1, which was expected because many other markers included in our multilocus dataset, mainly nuclear markers, are known to evolve slower. The results of the JML run are given in Table 1. All species pairs exhibit genetic distances that are not significantly lower than expected. Thus, we cannot reject the hypothesis of incomplete lineage sorting in any cases.

\section{Ecological niche modeling}

Figure 4 summarizes all distribution points for all STR species and Figure 5 summarizes climate variables used for the creation of ENMs. The ENMs for the 8 STR species analyzed, supplemented with other ecological data,

Table 1 Results of the JML run

\begin{tabular}{|c|c|c|c|c|c|c|c|c|c|c|}
\hline Distance obs./exp. & S. alp. & S. bar. & S. mea. & S. mon. & S. mun. & S. tar. & S. tas. & S. wec. & S. weh. & S. wil. \\
\hline S. alp. & & 4.83 & 2.42 & 4.83 & 2.42 & 2.42 & 2.42 & $1.21 \#$ & $1.21 \#$ & 4.83 \\
\hline S. bar. & 14.81 & & 4.83\# & 2.42\# & 4.83\# & 4.83 & 4.83 & $4.83+$ & 4.83 & 2.42 \\
\hline S. mea. & 4.44 & 0 & & 4.83\# & 2.42\# & 2.42 & 1.21 & $2.42+$ & 2.42\# & 4.83 \\
\hline S. mon. & 14.81 & 0 & 0 & & 4.83\# & 4.83 & 4.83 & $4.83+$ & 4.83 & 2.42 \\
\hline S. mun. & 1.48 & 0 & 0 & 0 & & 2.42 & 2.42\# & $2.42+$ & 2.42\# & 4.83 \\
\hline S. tar. & 5.92 & 23.70 & 8.89 & 23.70 & 4.44 & & 2.42 & 2.42 & $2.42+$ & 4.83 \\
\hline S. tas. & 5.93 & 22.22 & 8.89 & 22.22 & 0 & 5.93 & & 2.42 & 2.42\# & 4.83 \\
\hline S. wec. & 0 & 1.48 & 1.48 & 1.48 & 1.48 & 5.93 & 4.44 & & $1.21 \#$ & 4.83 \\
\hline S. weh. & 0 & 19.26 & 0 & 19.26 & 0 & 1.48 & 0 & 0 & & 4.83 \\
\hline S. wil. & 10.37 & 19.26 & 16.30 & 16.30 & 11.85 & 16.30 & 14.81 & 14.81 & 11.85 & \\
\hline
\end{tabular}

Minimum genetic distance $\left({ }^{*} 1,000\right)$, as estimated by JML, of STR species pairs. Lower left: observed minimum genetic distance. Upper right: expected minimum genetic distance (median). Species pairs in which the observed genetic distance is 0 due to the sharing of haplotypes are indicated by \#. Species pairs in which the observed minimum genetic distance is higher than the expected distance are indicated by + . There is no case in which the probability that the minimum observed genetic distance is lower than expected is significant $(p \leq 0.05)$. 

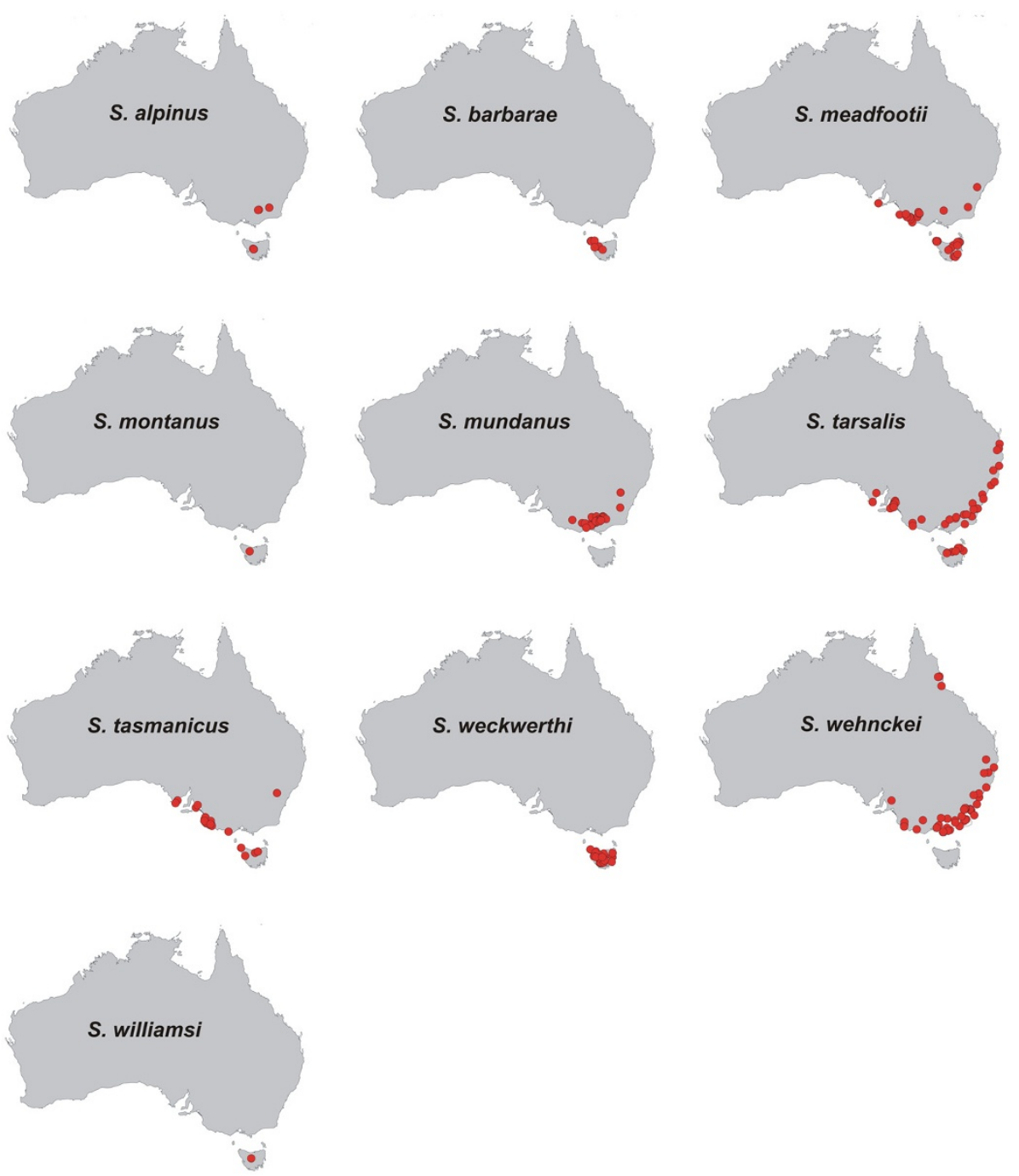

Figure 4 Distribution of species of the Sternopriscus tarsalis radiation. Red dots represent specimen localities used for ecological niche modeling.

are given in Figure 6. AUC values for all models range from 0.981 to 0.997 . Because all values are $>0.9$, the ability to distinguish presence from random background points is considered "very good" for all models according to Swets [60]. We preliminarily selected the climate layers "maximum temperature of the warmest month" (BIO5), "minimum temperature of the coldest month" (BIO6), "mean temperature of the wettest quarter" (BIO8), "mean temperature of the driest quarter" (BIO9), "precipitation of the wettest month" (BIO13), "precipitation of the driest month" (BIO14), "precipitation of the warmest quarter" (BIO18) and "precipitation of the coldest quarter" (BIO19). In our final selection, we omitted BIO13 and BIO14 because of correlation coefficients with other variables of $r^{2}>0.75$. Thus, all models presented here are based on six climate variables. Jackknifing to measure the importance of variables showed that either "maximum temperature of the warmest month" (BIO5: S. barbarae, S. weckwerthi, S. wehnckei), "mean temperature of the wettest quarter" (BIO8: S. alpinus, $S$. mundanus), or "precipitation of the coldest quarter" (BIO19: S. meadfootii, S. tarsalis, S. tasmanicus) were the most important variables in creating ENMs. Niche overlap values (I and D) and identity test results are given in Table 2. The results of the identity test are highly significant (Bonferroni corrected) for I in all and for D in nearly all pairwise species comparisons. However, the null hypothesis of identity in the ENMs of two compared species can be rejected only if the true calculated niche overlap is below the $99.9 \%$ confidence interval of the values generated in the identity test. In a few cases, the true calculated niche overlap is above this interval, and the null hypothesis of niche identity cannot be rejected [61]. 


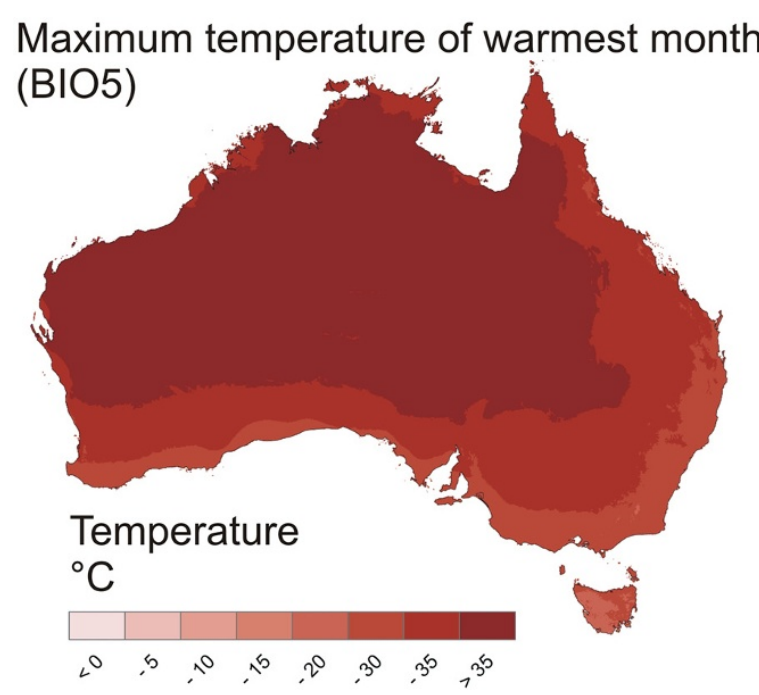

Mean temperature of the wettest quarter

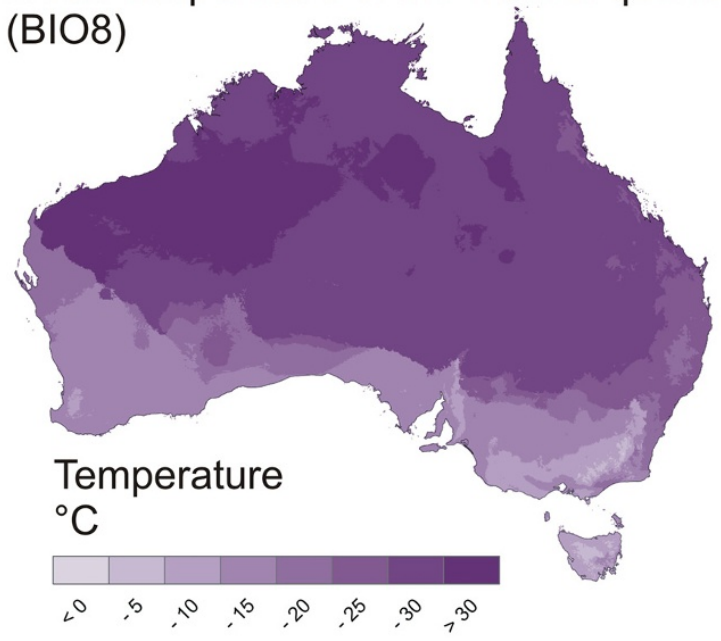

Precipitation of the warmest quarter

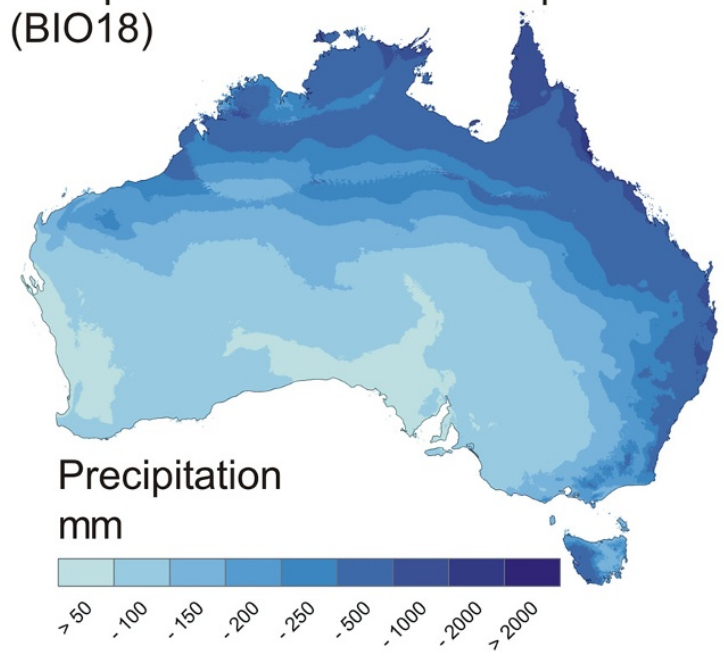

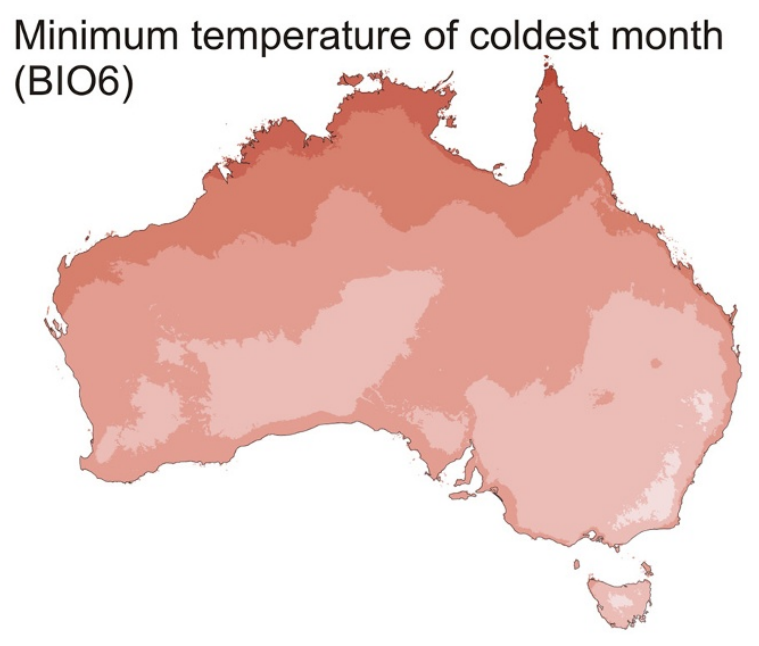

Mean temperature of the driest quarter

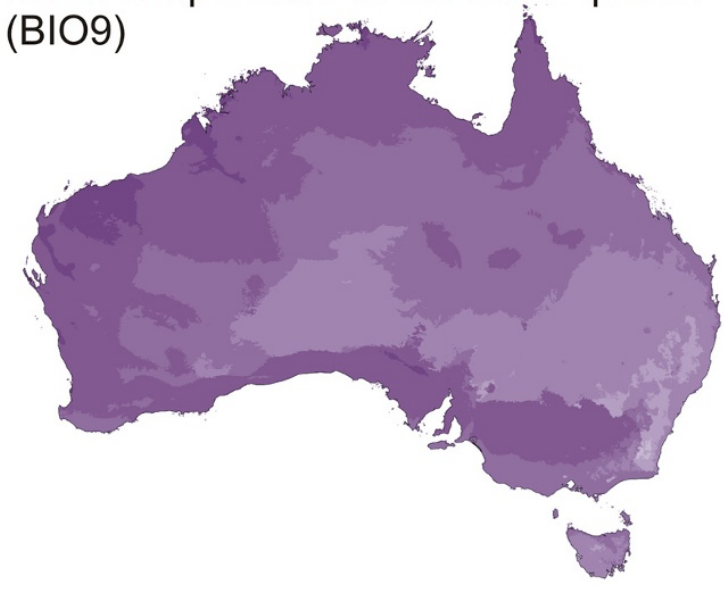

Precipitation of the coolest quarter (BIO19)

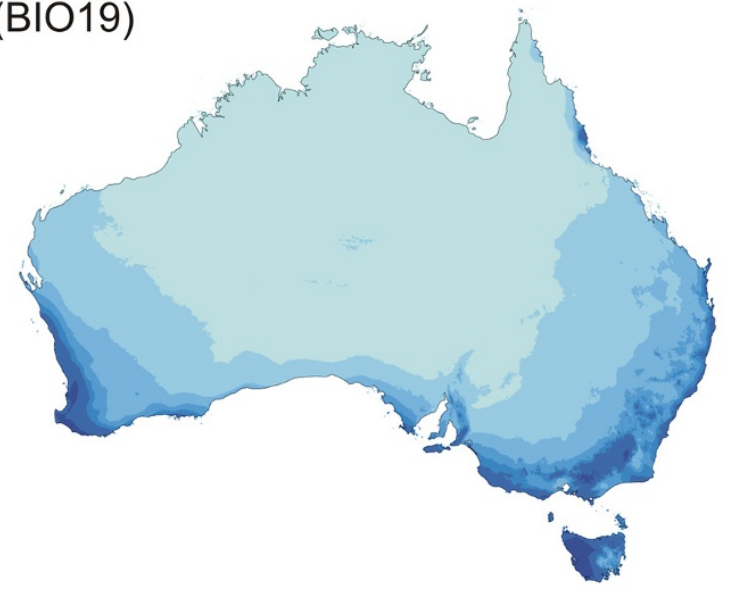




\section{Ecological analyses}

All species of the STR were compared for their preferences in altitude and habitat and for the most important climate factor in their ENM, which resulted from the jackknifing test in the ENM runs. Table 3 displays these three factors for all species coded by numbers for easy comparison. Only S. tasmanicus and S. tarsalis are identical in all three factors. S. montanus and S. williamsi might be identical to $S$. alpinus or S. weckwerthi depending on the most important climate factor, but no ENMs could be created. Within each of the three complexes in the $S$. tarsalis group, no two species are identical in all three factors.

\section{Discussion}

In the opening section of this article, we suggested three hypotheses: (1) species delimitation in the STR can be supported by genetic or ecological data; (2) the STR species originated in a rapid Pleistocene diversification event; and (3) Pleistocene climate oscillations promoted the radiation of the STR. In the following, we will discuss how our results support these hypotheses.

Our data shows that the molecular methods applied in our study do not serve to unambiguously distinguish and delimit the species of the STR. This is because of the widespread genotype sharing of mitochondrial genes and lack of diversification in nuclear genes between these species. However, the analysis of our ecological data shows that STR species appear to respond differently to ecological variables. Below, we initially discuss whether incomplete lineage sorting or hybridization may have caused the abundance of shared haplotypes in the STR. Then, we discuss the importance of the results of our ecological analyses in the context of the entire genus, and specifically for the STR.

Genotype sharings between species may be explained by incomplete lineage sorting, by hybridization, or a combination of both. Funk \& Omland [19] also mention imperfect taxonomy, inadequate phylogenetic information and paralogs as causes for genotype sharing. However, the taxonomy of Sternopriscus based on morphological characters is well supported $[27,28]$, and our multi-gene phylogeny is well supported by different analytical approaches. Paralogs can almost certainly be excluded because the patterns of species polyphyly are repeated by different mitochondrial and nuclear markers.

Hybridization, as a reason for genotype sharing in closely related species, has been proposed for various animal groups $[64,65]$, including groups with strong sexual selection (e.g., mating calls [66]), and has been shown to contribute to speciation [64]. However, in the case of Sternopriscus, the results of our analyses, the diversity in genital morphology, and the absence of specimens identifiable as hybrids, do not support hybridization [67]. Incomplete lineage sorting, or the retention of ancestral polymorphism, is the more likely explanation for genotype sharing in the case of the STR. Incomplete lineage sorting has often been recognized as a problem in resolving phylogenies of young and closely related taxa [68]. This phenomenon affects nuclear loci more commonly than faster evolving mitochondrial loci, but mitochondrial genes can be equally affected, particularly in closely related taxa where hardly any diversification in nuclear genes is found [19]. Incomplete lineage sorting as an explanation for haplotype sharings in the STR supports the view that the STR is a recent radiation.

A comparison of our ecological findings concerning the STR species with data on other Sternopriscus species shows that the STR occupies ecological ranges similar to those of other related species. The currently known altitudinal distribution and ecology of all Sternopriscus species in Australia is shown in Additional file 3: Table S3, modified after Hendrich \& Watts [27,28]. 10 species of the genus are rheophilic and inhabit rivers and streams that are mainly of intermittent character. 11 species are acidophilic and live in seasonal or permanent swamps, ponds and pools of different types of peatlands. 7 species appear to be more or less eurytopic and occur in various water bodies in open or forested country. The highest species diversity is in lowland or coastal areas and hilly or low mountain ranges from 0 to $500 \mathrm{~m}$. Only 6 species were collected at $1000 \mathrm{~m}$ or above (S. alpinus, S. meadfootii, S. montanus, S. mundanus, S. williamsi and S. weckwerthi).

Within the STR, all species inhabit broadly overlapping areas in mesic southeast Australia, except for a few localities of $S$. wehnckei in the northeast (the Eastern Coastal Australia region and small parts of the Murray-Darling region of Abell et al. [29]. Many species also inhabit Tasmania, including two endemics (Bass Strait Drainages and Southern Tasmania). ENMs indicate niche diversification within this group of closely related and broadly sympatric species. Aside from the high levels of significance in the identity test, the degree of niche diversification is hard to measure. Therefore, we rely on the importance of the various climate variables used to characterize the species ENMs. The variables of highest importance are 


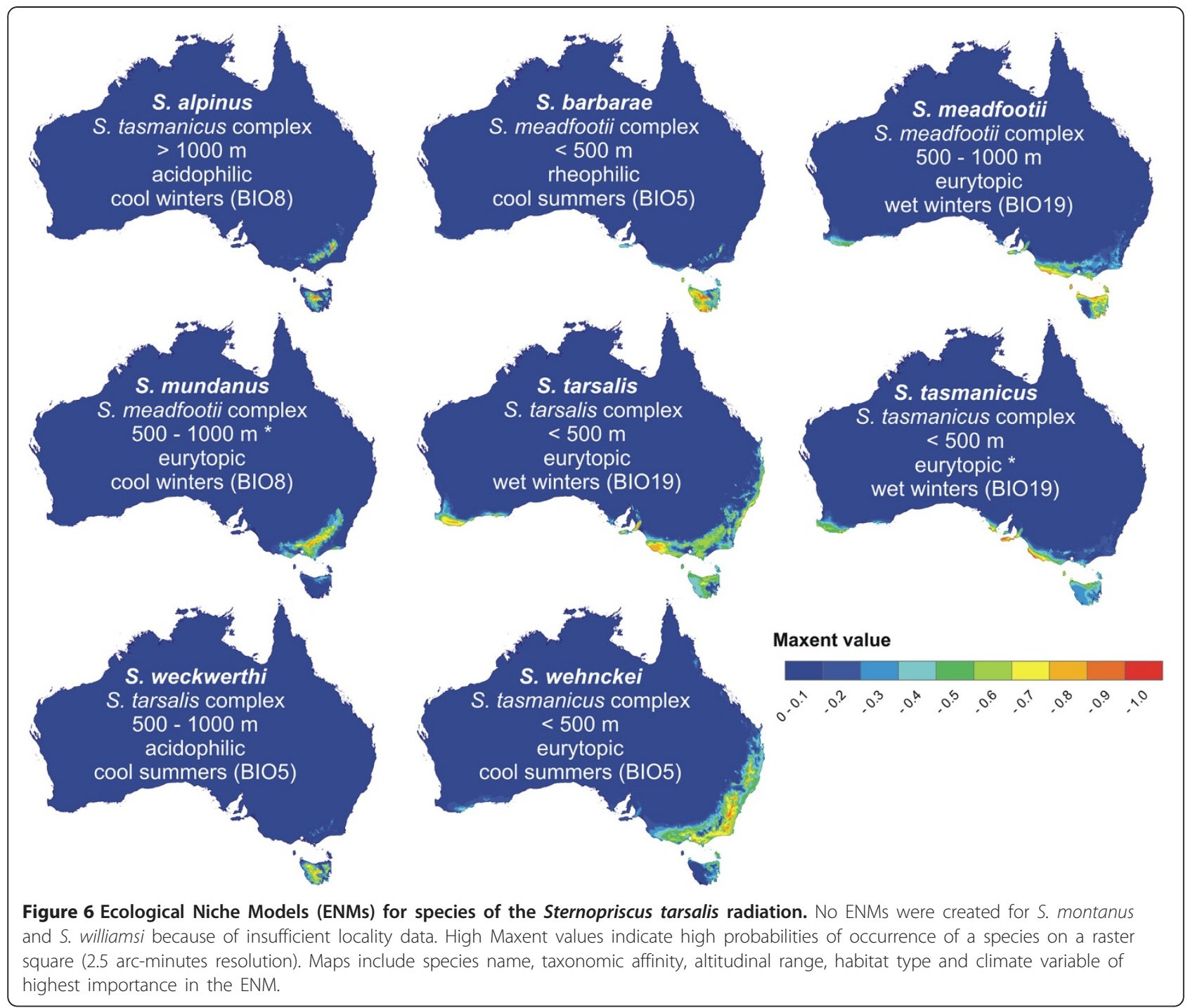

"maximum temperature of the warmest month" (BIO5), "mean temperature of the wettest quarter" (BIO8), or "precipitation of the coldest quarter" (BIO19). Figure 5 shows that all the species studied inhabit areas with relatively low maximum temperatures, with the lowest on Tasmania. The two species most characterized by this factor are the two Tasmanian endemics, S. barbarae and S. weckwerthi. A distinction between the two remaining factors is more

Table 2 Results of the niche identity test

\begin{tabular}{|c|c|c|c|c|c|c|c|c|}
\hline Overlap D/I & S. alp. & S. bar. & S. mea. & S. mun. & S. tar. & S. tas. & S. wec. & S. weh. \\
\hline S. alp. & 0 & $0.674^{* *}$ & $0.682^{* *}$ & $0.676^{* *}$ & $0.661^{*} \#$ & $0.651^{* * \#}$ & $0.648^{* *}$ & $0.571^{* *}$ \\
\hline S. bar. & $0.506^{* *}$ & 0 & $0.733^{* *} \#$ & $0.569^{* *}$ & $0.680^{* *} \#$ & $0.735^{* *} \#$ & $0.755^{* *}$ & $0.582^{* *}$ \\
\hline S. mea. & $0.481^{* *}$ & $0.589^{* * \#}$ & 0 & $0.691^{* *}$ & $0.801^{* *}$ & $0.847^{* * \#}$ & $0.606^{* *}$ & $0.684^{* *}$ \\
\hline S. mun. & $0.474^{* *}$ & $0.327^{* *}$ & $0.496^{* *}$ & 0 & $0.661^{* *}$ & $0.602^{* *}$ & $0.520^{* *}$ & $0.637^{* *}$ \\
\hline S. tar. & 0.476 & 0.472 & $0.711^{* *}$ & $0.456^{* *}$ & 0 & $0.759^{* *}$ & $0.548^{* *}$ & $0.756^{* *}$ \\
\hline S. tas. & $0.433^{* *}$ & 0.560 & $0.762^{* *} \#$ & $0.378^{* *}$ & $0.648^{* *}$ & 0 & $0.583^{* *}$ & $0.627^{* *}$ \\
\hline S. wec. & $0.451^{* *}$ & $0.642^{* *}$ & $0.367^{* *}$ & $0.241^{* *}$ & $0.282^{* *}$ & $0.331^{* *}$ & 0 & $0.459^{* *}$ \\
\hline S. weh. & $0.374^{* *}$ & $0.356^{* *}$ & $0.523^{* *}$ & $0.444^{* *}$ & $0.639^{* *}$ & $0.419^{* *}$ & $0.177^{* *}$ & 0 \\
\hline
\end{tabular}

Niche overlap values ( $D$ and $I)$, calculated with ENMtools, are given for species pairs and are mostly lower than the randomized overlap levels generated in the identity test at significant $(*, p \leq 0.05$, Bonferroni corrected) or highly significant $(* *, p \leq 0.001$, Bonferroni corrected) level. This means that niches are more divergent than expected at random. In some cases, results are not significant, or significantly higher than the randomized overlap (indicated by \#). In these cases, niches are not more divergent than expected by random. Note that results yielded by $D$ and I do not accord in all cases. 
Table 3 Taxonomic affinities and ecological preferences of species in the Sternopriscus tarsalis radiation

\begin{tabular}{lllll}
\hline Species & Complex & Altitude & Habitat & Climate \\
\hline S. alpinus & 2 & 2 & 2 & 1 \\
S. tasmanicus & 2 & 0 & $1^{*}$ & 2 \\
S. wehnckei & 2 & 0 & 1 & 0 \\
S. barbarae & 1 & 0 & 0 & 0 \\
S. meadfootii & 1 & 1 & 1 & 2 \\
S. montanus & 1 & 2 & 2 & $?$ \\
S. mundanus & 1 & $1^{* *}$ & 2 & 1 \\
S. tarsalis & 0 & 0 & 1 & 2 \\
S. weckwerthi & 0 & 2 & 2 & 0 \\
S. williamsi & 1 & 1 & 2 & $?$
\end{tabular}

Complex: $0=S$. tarsalis, $1=S$. meadfootii, $2=S$. tasmanicus. Altitude: preferred altitude range, $0=<500 \mathrm{~m}, 1=500-1000 \mathrm{~m}, 2=>1000 \mathrm{~m}$. Habitat: $0=$ rheophilic, 1 = eurytopic, $2=$ acidophilic. Climate: according to the dominating climate variables in the ENM, $0=$ cool summers, $1=$ cool winters, $2=$ wet winters. *: Also occurs in habitats with moderate salinity. ${ }^{* *}$ : Actual altitudinal range is $200-1550 \mathrm{~m}$.

difficult. Considering Figure 5, "mean temperature of the wettest quarter" is lowest in areas where winters (the wettest quarter in our region of interest) are cold, whereas "precipitation of the coldest quarter" is highest where winters are wet. Some species (e.g., the high-altitude S. alpinus) may be tolerant of winter temperatures that are too low for other species, whereas other species are more dependent on sufficient precipitation. Species that require the latter are eurytopic species that also inhabit ephemeral waters, such as ponds at the edge of rivers and creeks, which are only filled after heavy rainfall. The acidophilic species, which inhabit more permanent water bodies with dense vegetation, are often "cold winter" species.

The low divergences between haplotypes in the STR species suggest that these species originated in a recent and rapid radiation. Unfortunately, we could not rely on any calibration points to support our molecular clock approach. Instead, we attempted to estimate the origin of the STR based on standard cox1 mutation rates [44,45]. We estimated an origin of c. 0.96 to 1.48 MYA, which leads to an estimated speciation rate of 2.40 or 1.56 species per MY. Genetic distance might indicate the age of the ancestral species, however divergence time estimates for the extant species should not be considered reliable beyond assumption of a comparably recent origin of the STR. This fact alone, however, suggests that the STR is an exceptional event for what is known of aquatic beetles. For other insect groups, little evidence exists for similarly fast diversification events. The fastest rate (4.17 species per MY) was estimated for a clade of 6 species of Hawaiian crickets over 0.43 MY [16]. However, in the same study, for a related clade comprising 11 species, the estimated rate was much lower at 1.26 species per MY over 1.9 MY. Additional estimates are available for Galagete moths in the Galapagos [17] of 0.8 species per MY $(\mathrm{n}=12, \mathrm{t}=1.8 \mathrm{MY})$ and for Japanese Ohomopertus ground beetles [18] of $1.92(\mathrm{n}=15, \mathrm{t}=1.4$ $\mathrm{MY})$ to 2.37 species per MY $(\mathrm{n}=6, \mathrm{t}=0.76 \mathrm{MY})$. The average speciation rate in insects was proposed to be 0.16 species per MY [15]. This comparison shows that rapid radiation events, as exemplified in the STR, appear to be exceptional among insects and particularly in continental faunas because all other examples recorded were island radiations.

Species groups that originated from rapid radiation events have been detected in almost all organismic groups and habitats [69]. An overview of many recent and past events suggests three major promoters of rapid radiations: the appearance of a key innovation that allows the exploitation of previously unexploited resources or habitats [70], the availability of new resources [71], and the availability of new habitats, e.g., because of a rare colonization event or drastic environmental changes [72,73]. In the case of the STR, we find no evident key innovation distinguishing this group from other Sternopriscus species. We have no data concerning internal morphology or physiology. Additionally, our data show that the observation that STR species have ecological requirements similar to those of other Sternopriscus species does not indicate the presence of any key innovations. There is also no indication of any new resource that could be specifically exploited by the STR species. Therefore, we explore the possibility that drastic environmental changes during the Pleistocene climate oscillations mediated the radiation of the STR species.

During most of the Cenozoic, the climate of Australia was hot and humid and currently remains so in the northern rainforest areas [11]. Aridification began in the Miocene (c. 15 MYA) and gradually led to the disappearance of forests and to the spread of deserts over much of the present continent. Most of today's sand deserts, however, are geologically younger and appeared only after the final boost of aridification that accompanied the Ice Ages, particularly since the later Pleistocene (c. 0.9 MYA). The climate was subjected to large oscillations in temperature and rainfall, which drove many groups of organisms into refugia and also promoted speciation $[12,13]$. Our results also document a strong and abrupt increase in speciation in the genus Sternopriscus about 1 to 1.5 MYA, represented by the STR. This age estimate is congruent with the Pleistocene oscillations. Byrne et al. [12] present cases of organisms restricted to mesic habitats that were formerly most likely more widespread, but today occupy relictual areas with suitable climates. However, some of the young species of the STR occupy rather large areas in southwestern Australia. This distribution indicates good dispersal abilities, which are 
necessary for organisms that inhabit habitats of relatively low persistence [74]. Ribera \& Vogler [75] argue that for this reason, beetle species that inhabit lentic aquatic habitats often have better dispersal abilities than those inhabiting lotic habitats. However, it is possible that the STR species of lotic habitats only recently derived from an ancestor adapted to lentic habitats with good dispersal abilities that are maintained in the newly derived species.

Speciation in Pleistocene refugia was previously described for dytiscid beetles on the Iberian Peninsula [9]. During the Pleistocene climate oscillations, the ancestral species of the STR might have been forced into ongoing cycles of retreating into, and the re-expansion from, refugia. Under the recurrent, extremely unsuitable climate conditions, the isolation of small populations over many generations might have promoted speciation and the fixation of morphological traits. This scenario might also explain the lack of clear geographic or taxonomic structuring in the striking haplotypic diversity presented by the STR species. This diversity might be attributed to the cycles of expansion and retreat that repeatedly isolated haplotypes in various geographic locations before newly allowing the expansion and colonization of other areas.

The phenomenon of groups of young and closely related species within a defined distributional range is most familiar in ichthyology, in which it was termed "species flock". Among the most prominent species flocks are the cichlids of the African Great Lakes and other lake ecosystems around the world, the Sailfin Silversides of Sulawesi, and the Notothenioid Antarctic Ice Fishes (see review in Schön \& Martens [76]). Schön \& Martens [76] summarize the criteria for naming a group of species a species flock as "speciosity [= species-richness], monophyly and endemicity". Compared with the large fish species flocks, the STR is poor in species. Nevertheless, the number of species is "disproportionally high" [77] in relation to the surrounding areas, as no other region in Australia is inhabited by a comparable assemblage of closely related species. In the last decade, an increasing number of less species-rich radiations have been termed species flocks with as little as 3 or 4 species $[76,78]$. Most other species flocks inhabit lakes, islands or archipelagoes. These are areas more "narrowly circumscribed" [77] than the area of endemism of the STR, which can be broadly termed "the southeast Australian region". Most STR species have relatively large ranges that do not share a common limit and sometimes do not even overlap. Our results show that STR species often occupy different habitat types. Additionally, the clade is not strictly endemic to southeastern Australia, as shown by the northeastern records of $S$. wehnckei. Based on this criterion, other rapid radiations among insects $[16,17]$ are much more adequate examples of species flocks.

\section{Conclusions}

Our results provide evidence that STR species are the result of an extremely recent, most likely Pleistocene, radiation. The STR species cannot be distinguished with the molecular methods used in this study, however, the species show clear divergences in their responses to ecological factors of habitat type and climate. We proposed a scenario in which the Pleistocene climate oscillations led to the repeated restriction and expansion of the ranges of the ancestral species of the STR, which may have promoted fixation of ecological adaptations and morphological traits in small and isolated populations restricted to refugia. This suggests that Sternopriscus is an example for the hypothesis that Pleistocene refugia promoted speciation.

Taking this scenario into account, the STR does not appear as an evolving or fully evolved species flock but as a radiation based on a species flock. While possibly confined to a narrowly circumscribed area during the Pleistocene, the STR species were able to break the boundaries of their refugia with the end of the Ice Ages and increase their ranges. Today, because the species are no longer confined to a common limited area, the term "species flock" may best fit a stage in speciation the STR has previously passed.

\section{Additional files}

Additional file 1: Table S1. Sequences of primers used for PCR and sequencing. Forward ( $F$ ) and reverse (R) primers are given. Mitochrondrial gene loci: $\mathrm{CO} 1=$ cytochrome $\mathrm{C}$ oxidase 1, CytB = cytochrome B oxidase, $16 \mathrm{~S}=16 \mathrm{~S}$ ribosomal RNA. Nuclear gene loci: $\mathrm{H3}=$ histone $3, \mathrm{H} 4=$ histone $4, \mathrm{ARK}=$ arginine kinase, 18 $\mathrm{S}=18 \mathrm{~S}$ ribosomal RNA. I = inosine.

Additional file 2: Table S2. Localities of Sternopriscus species used in Ecological Niche Modeling. Coordinates are given in decimal degrees.

Additional file 3: Table S3. Ecological data on all Sternopriscus species. Data from Hendrich \& Watts $[27,28]$.

\section{Abbreviations}

ENM: Ecological niche modeling; MST: Minimum spanning tree; MY: Million years; MYA: Million years ago; STR: Sternopriscus tarsalis radiation.

\section{Competing interests}

The authors declare that they have no competing interests.

\section{Authors' contributions}

$\mathrm{OH}$ performed the laboratory work, the molecular genetic studies, the diversification analyses, the ecological niche modeling and analyses, and drafted the manuscript. LH collected the samples and ecological data and helped to draft the manuscript. ME coordinated the diversification analyses. EFAT conducted the phylogeographic analyses. MJG conducted the analysis of hybridization vs. incomplete lineage sorting. MB conceived the study, participated in its design and coordination, and helped to draft the manuscript. All authors read and approved the final manuscript.

\section{Acknowledgements}

This work and ongoing research on the Australian water beetle fauna was supported by grants from the German Research Foundation (DFG) to Lars Hendrich (HE5729/1-1) and Michael Balke (BA2152/7-1). We are grateful to the Department of Environment and Conservation in Western Australia for 
giving us permission to conduct scientific research in Western Australia (Permit numbers: SF 003017 and NE 002348), and the Parks and Wildlife Commission of the Northern Territory for giving us permission to conduct scientific research in the Northern Territory (Permit Number: 23929 and RK400/RK- 660). We are further grateful to the Department of Environment and Conservation in New South Wales (Scientific License No. S12040) for giving us permission to conduct scientific research in the National and State Parks. We thank the CIPRES portal for computing resources, Amanda Glaser and Jeannine Marquardt, Munich, for their assistance in the phylogenetic analyses, and Ulrich Schliewen, Munich, Jesús Gómez-Zurita, Barcelona, and the editor and two anonymous referees for greatly improving this manuscript with their comments.

\section{Author details}

'Zoologische Staatssammlung, Münchhausenstr. 21, Munich 81247, Germany. ${ }^{2}$ Department of Organismic and Evolutionary Biology, Harvard University, 26 Oxford Street, Cambridge, MA 02138, USA. ${ }^{3}$ School of Biological Sciences, University of Bristol, Woodland Road, Bristol BS8 1UG, UK. ${ }^{4}$ GeoBioCenter, Ludwig-Maximilians-Universität, Richard-Wagner-Str. 10, Munich 80333, Germany.

Received: 27 February 2012 Accepted: 30 July 2012

Published: 9 August 2012

\section{References}

1. Barraclough TG, Vogler AP, Harvey PH: Revealing the factors that promote speciation. Phil Trans R Soc B 1998, 353:241-249.

2. Hillebrand $\mathrm{H}$ : On the generality of the latitudinal diversity gradient. Am Nat 2004, 163:192-211.

3. Mittelbach GG, Schemske DW, Cornell HV, Allen AP, Brown JM, Bush MB, Harrison SP, Hurlbert AH, Knowlton N, Lessios HA, McCain CM, McCune AR, McDade LA, McPeek MA, Near TJ, Price TD, Ricklefs RE, Roy K, Sax DF, Schluter D, Sobel JM, Turelli M: Evolution and the latitudinal diversity gradient: speciation, extinction and biogeography. Ecol Lett 2007, 10:315-331.

4. Benton MJ: When life nearly died: The greatest mass extinctions of all time. London, UK: Thames \& Hudson; 2005.

5. Ricklefs RE: Estimating diversification rates from phylogenetic information. Trends Ecol Evol 2007, 22:601-610.

6. Quental TB, Marshall CR: Diversity dynamics: molecular phylogenies need the fossil record. Trends Ecol Evol 2010, 25:434-441.

7. Hewitt GM: Genetic consequences of climatic oscillations in the Quaternary. Phil Trans R SOC B 2004, 359:183-195.

8. Beheregaray LB: Twenty years of phylogeography: the state of the field and the challenges for the Southern Hemisphere. Mol Ecol 2008, 17:3754-3774

9. Ribera I, Vogler AP: Speciation of Iberian diving beetles in Pleistocene refugia (Coleoptera, Dytiscidae). Mol Ecol 2004, 13:179-193.

10. Jansson R, Dynesius M: The fate of clades in a world of recurrent climatic change: Milankovitch oscillations and evolution. Ann Rev Ecol Syst 2002, 33:741-777

11. Frakes LA, McGowran B, Bowler JM: Evolution of Australian Environments. In Fauna of Australia. General Articles. 1Ath edition. Edited by Dyne GR, Walton DW. Canberra: Australian Government Publishing Service; 1987:1-17.

12. Byrne M, Yeates DK, Joseph L, Kearney M, Bowler J, Williams MAJ, Cooper S, Donnellan SC, Keogh JS, Leys R, Melville J, Murphy DJ, Porch N, Wyrwoll KH: Birth of a biome: insights into the assembly and maintenance of the Australian arid zone biota. Mol Ecol 2008, 17:4398-4417.

13. Pepper M, Doughty P, Hutchinson MN, Keogh JS: Ancient drainages divide cryptic species in Australia's arid zone: Morphological and multi-gene evidence for four new species of Beaked Geckos (Rhynchoedura). Mol Phylogenet Evol 2011, 61:810-822.

14. Leys R, Watts CHS, Cooper SJB, Humphreys WF: Evolution of subterranean Diving Beetles (Coleoptera: Dytiscidae: Hydroporini, Bidessini) in the arid zone of Australia. Evolution 2003, 57:2819-2834.

15. Coyne JA, Orr HA: Speciation. Sunderland, MA: Sinauer Ass; 2004

16. Mendelson TC, Shaw KL: Sexual behavior: Rapid speciation in an arthropod. Nature 2005, 433:375-376.

17. Schmitz P, Cibois A, Landry B: Molecular phylogeny and dating of an insular endemic moth radiation inferred from mitochondrial and nuclear genes: The genus Galagete (Lepidoptera: Autostichidae) of the Galapagos Islands. Mol Phylogenet Evol 2007, 45:180-192.

18. Sota T, Nagata N: Diversification in a fluctuating island setting: rapid radiation of Ohomopterus ground beetles in the Japanese Islands. Phil Trans R SOC B 2008, 363:3377-3390.

19. Funk DJ, Omland KE: Species-level paraphyly and polyphyly: frequency, causes, and consequences, with insights from animal mitochondrial DNA. Annu Rev Ecol Evol Syst 2003, 34:397-423.

20. Degnan JH, Rosenberg NA: Discordance of species trees with their most likely gene trees. PLoS Genetics 2006, 2:762-768.

21. Heled J, Drummond AJ: Bayesian inference of species trees from multilocus data. Mol Biol Evol 2010, 27:570-580.

22. Graham CH, Ron SR, Santos JC, Schneider CJ, Moritz C: Integrating phylogenetics and environmental niche models to explore speciation mechanisms in dendrobatid frogs. Evolution 2004, 58:1781-1793.

23. Soberón J, Peterson AT: Interpretation of models of fundamental ecological niches and species' distributional areas. Biodiv Infor 2005, 2:1-10.

24. Guisan A, Zimmermann N: Predictive habitat distribution models in ecology. Ecol Model 2000, 135:147-189.

25. Hawlitschek O, Porch N, Hendrich L, Balke M: Ecological niche modelling and $\mathrm{nDNA}$ sequencing support a new, morphologically cryptic beetle species unveiled by DNA barcoding. PLoS One 2011, 6:e16662.

26. Kozak KH, Wiens JJ: Does niche conservatism promote speciation? A case study in North American salamanders. Evolution 2006, 60:2604-2621.

27. Hendrich L, Watts CHS: Taxonomic revision of the Australian genus Sternopriscus Sharp, 1882 (Coleoptera: Dytiscidae, Hydroporinae). Koleopterol Rdsch 2004, 74:75-142

28. Hendrich L, Watts CHS: Update of Australian Sternopriscus Sharp, 1882 with description of three new species (Coleoptera: Dytiscidae: Hydroporinae). Koleopterol Rdsch 1882, 77:49-59.

29. Abell R, Thieme M, Revenga C, Bryer M, Kottelat M, Bogutskaya N, Coad B, Mandrak N, Contreras-Balderas S, Bussing W, Stiassny ML, Skelton P, Allen GR, Unmack P, Naseka A, Ng R, Sindorf N, Robertson J, Armijo E, Higgins J, Heibel TJ, Wikramanayake E, Olson D, Lopez HL, Reis RE, Lundberg JG, Sabaj Perez MH, Petry P: Freshwater ecoregions of the world: a new map of biogeographic units for freshwater biodiversity conservation. BioScience 2008, 58:403-414.

30. Hendrich L, Pons J, Ribera I, Balke M: Mitochondrial Cox1 sequence data reliably uncover patterns of insect diversity but suffer from high lineageidiosyncratic error rates. PLoS One 2010, 5:e14448.

31. Posada D: jModelTest: Phylogenetic model averaging. Mol Biol Evol 2008, 25:1253-1256.

32. Huelsenbeck JP, Ronquist F: MrBAYES: Bayesian inference of phylogenetic trees. Bioinformatics 2001, 17:754-755.

33. Rambaut A, Drummond AJ: Tracer v1.4. 2007. http://beast.bio.ed.ac.uk/Tracer

34. Silvestro D, Michalak I: raxmIGUI: a graphical front-end for RAxML. Org Divers Evol 2012, in press.

35. Goloboff PA, Farris JS, Nixon KC: TNT, a free program for phylogenetic analysis. Cladistics 2008, 24:774-786.

36. Edgar RC: MUSCLE: multiple sequence alignment with high accuracy and high throughput. Nucleic Acids Res 2004, 32:1792-1797.

37. Tamura K, Peterson D, Peterson N, Stecher G, Nei M, Kumar S: MEGA5: Molecular evolutionary genetics analysis using maximum likelihood, evolutionary distance, and maximum parsimony methods. Mol Biol Evol 2011, 28:2731-2739.

38. Paradis E, Claude J, Strimmer K: APE: analyses of phylogenetics and evolution in R language. Bioinformatics 2004, 20:289-290.

39. Rabosky DL: LASER, a maximum likelihood toolkit for detecting temporal shifts in diversification rates from molecular phylogenies. Evol Bioinform Online 2006, 2:247-250.

40. Nee S, Holmes EC, May RM, Harvey PH: Extinction rates can be estimated from molecular phylogenies. Phil Trans R Soc B 1994, 344:77-82.

41. Pybus $\mathrm{OG}$, Harvey $\mathrm{PH}$ : Testing macroevolutionary models using incomplete molecular phylogenies. Proc R Soc B 2000, 267:2267-2272.

42. Rabosky DL: Likelihood methods for detecting temporal shifts in diversification rates. Evolution 2006, 60:1152-1164.

43. Papadopoulou A, Anastasiou I, Vogler AP: Revisiting the insect mitochondrial molecular clock: Mid-Aegean trench calibration. Mol Biol Evol 2010, 27:1659-1672. 
44. Brower AVZ: Rapid morphological radiation and convergence among races of the butterfly Heliconius erato inferred from patterns of mitochondrial DNA Evolution. Proc Natl Acad Sci USA 1994, 91:6491-6495.

45. $\mathrm{Fu} \mathrm{YH}$ : Statistical tests of neutrality of mutations against population growth, hitchhiking and background selection. Genetics 1997, 147:915-925.

46. Tajima F: Statistical method for testing the neutral mutation hypothesis by DNA polymorphism. Genetics 1989, 123:585-595.

47. Librado P, Rozas J: DnaSP v5: A software for comprehensive analysis of DNA polymorphism data. Bioinformatics 2009, 25:1451-1452.

48. Excoffier $L$, Lischer HEL: Arlequin suite ver 3.5: A new series of programs to performpopulation genetics analyses under Linux and Windows. Mol Ecol Res 2010, 10:564-567.

49. Teacher AGF, Griffiths DJ: HapStar: Automated haplotype network layout and visualisation. Mol Ecol Res 2011, 11:151-153.

50. Joly S, McLenachan PA, Lockhart PJ: A statistical approach for distinguishing hybridization and incomplete lineage sorting. Am Nat 2009, 174:54-70.

51. Joyce DA, Lunt DH, Genner MJ, Turner GF, Bills R, Seehausen O: Repeated colonization and hybridization characterize the Lake Malawi cichlid fish species flock. Curr Biol 2011, 21:108-109.

52. Genner MJ, Turner GF: Ancient hybridization and phenotypic novelty within Lake Malawi's cichlid fish radiation. Mol Biol Evol 2012, 29:195-206.

53. Nylander JAA: MrModeltest v2. Uppsala University: Program distributed by the author. Evolutionary Biology Centre; 2004.

54. Joly S: JML: testing hybridization from species trees. Mol Ecol Res 2012, 12:179-184.

55. Hijmans RJ, Cameron SE, Parra JL, Jones PG, Jarvis A: Very high resolution interpolated climate surfaces for global land areas. Int J Climatol 2005, 2:1965-1978.

56. Warren DL, Glor RE, Turelli M: Environmental niche equivalency versus conservatism: quantitative approaches to niche evolution. Evolution 2008, 62:2868-2883.

57. Phillips SJ, Anderson RP, Schapire RE: Maximum entropy modelling of species geographic distributions. Ecol Model 2006, 190:231-259.

58. Phillips SJ, Dudík M, Elith J, Graham CH, Lehmann A, Leathwick J, Ferrier S: Sample selection bias and presence-only distribution models: implications for background and pseudo-absence data. Ecol App/ 2009, 19:181-197.

59. Swets K: Measuring the accuracy of diagnostic systems. Science 1988, 240:1285-1293.

60. Warren DL, Glor RE, Turelli M: ENMTools: a toolbox for comparative studies of environmental niche models. Ecography 2010, 33:607-611.

61. Rabosky DL, Lovette IJ: Explosive evolutionary radiations: decreasing speciation or increasing extinction through time? Evolution 2008, 62:1866-1875.

62. Rogers $A R$, Harpending $H$ : Population growth makes waves in the distribution of pairwise genetic differences. Mol Biol Evol 1992, 9:552-569.

63. Salzbuger W, Baric S, Sturmbauer C: Speciation via introgressive hybridization in East African cichlids? Molec Ecol 2002, 11:619-625.

64. Grant PR, Grant BR, Petren K: Hybridization in the recent past. Am Nat 2005, 166:56-67.

65. Vedenina $\mathrm{V}$ : Variation in complex courtship traits across a hybrid zone between grasshopper species of the Chorthippus albomarginatus group. Biol J Linn Soc 2011, 102:275-291.

66. Usami T, Yokoyama J, Kubota K, Kawata M: Genital lock-and-key system and premating isolation by mate preference in Carabid beetles (Carabus subgenus Ohomopterus). Biol J Linn Soc 2006, 87:145-154.

67. Takahashi K, Terai Y, Nishida M, Okada N: Phylogenetic relationships and ancient incomplete lineage sorting among Cichlid fishes in Lake Tanganyika as revealed by analysis of the insertion of retroposons. $\mathrm{Mol}$ Biol Evol 2001, 18:2057-2066.

68. Schluter D: The ecology of adaptive radiation. Oxford, UK: Oxford University Press; 2000.

69. Nitecki MH: Evolutionary innovations. Chicago, IL: The University of Chicago Press; 2000.

70. Farrell BD, Mitter C: Adaptive radiation in insects and plants: time and opportunity. Am Zool 1994, 34:57-69.

71. Simpson GG: The major features of evolution. New York: Columbia University Press; 1953.
72. Grant PR: Ecology and evolution of Darwin's Finches. Princeton, NJ: Princeton University Press; 1984

73. Balke M, Ribera I, Hendrich L, Miller MA, Sagata K, Posman A, Vogler AP, Meier R: New Guinea highland origin of a widespread arthropod supertramp. Proc R Soc B 2009, 276:2359-2367.

74. Ribera I, Vogler AP: Habitat type as a determinant of species range sizes: the example of lotic-lentic differences in aquatic Coleoptera. Biol J Lin Soc 2000, 71:33-52.

75. Greenwood PH: What is a species flock? In Evolution of fish species flocks. Edited by Echelle AA, Kornfield I. Maine: Orono Press; 1994:13-19.

76. Schön I, Martens K: Adaptive, pre-adaptive and non-adaptive components of radiations in ancient lakes: a review. Org Divers Evol 2004, 4:137-156.

77. Albrecht C, Trajanovski S, Kuhna K, Streita B, Wilke T: Rapid evolution of an ancient lake species flock: Freshwater limpets (Gastropoda: Ancylidae) in the Balkan Lake Ohrid. Org Divers Evol 2006, 6:294-307.

78. Miller MA, Pfeiffer W, Schwartz T: Creating the CIPRES Science Gateway for inference of large phylogenetic trees. In Proceedings of the Gateway Computing Environments Workshop (GCE), 14 Nov. 2010. New Orleans, Louisiana; 2010:1-8. http://www.ngbw.org/ee/index.php/portal/cite_us.

doi:10.1186/1471-2148-12-142

Cite this article as: Hawlitschek et al:: Pleistocene climate change promoted rapid diversification of aquatic invertebrates in Southeast Australia. BMC Evolutionary Biology 2012 12:142.

\section{Submit your next manuscript to BioMed Central and take full advantage of:}

- Convenient online submission

- Thorough peer review

- No space constraints or color figure charges

- Immediate publication on acceptance

- Inclusion in PubMed, CAS, Scopus and Google Scholar

- Research which is freely available for redistribution
C Biomed Central 